International Journal of Child, Youth, and Family Studies (2014): 5(4.1) 649-665

\title{
REFLECTIONS ON RESEARCHING WITH CHILDREN USING “FAMILY GROUP INTERVIEWS” AS PART OF A QUALITATIVE LONGITUDINAL STUDY
}

\author{
Alice MacLean and Jeni Harden
}

\begin{abstract}
Family sociologists often conduct research which generates and compares parents' and children's perspectives as a way of ensuring children's voices are heard and building an understanding of family practices and cultures. It is far less common, however, for children to be interviewed in the presence of parents or to interview families as a group. Primarily, this is a response to concerns that, given generational power relations, the presence of parents may serve to influence, police, or silence children's voices. However, by making such methodological assumptions and, in turn, not generating group accounts with parents and children, we may be missing opportunities to add further methods to our toolkit and additional analytical dimensions to our explorations and understandings of families' and children's lives. In this article, we reflect on our experiences of conducting family group interviews as the second wave of a qualitative longitudinal study, involving parents and children who gave individual accounts at the first and third/final waves. We explore the factors involved in designing this method into a research project, the challenges of conducting family group interviews, and of analysing the data produced. In so doing, we contribute to the methodological debate on researching with children in the context of families.
\end{abstract}

Keywords: qualitative longitudinal research, families, group interviews, children, parents

Alice MacLean, Ph.D. (the corresponding author) is an investigator scientist at the CSO/MRC Social and Public Health Sciences Unit, University of Glasgow, Top Floor, 200 Renfield Street, Glasgow, United Kingdom, G2 3QB. E-mail: alice.maclean@glasgow.ac.uk.

Jeni Harden, Ph.D. is a senior lecturer at the Centre for Population Health Sciences, University of Edinburgh, Teviot Place, Edinburgh, United Kingdom, EH8 9AG.

E-mail: jeni.harden@ed.ac.uk. 
International Journal of Child, Youth, and Family Studies (2014): 5(4.1) 649-665

Family sociologists often conduct research which generates and compares parents' and children's perspectives as a way of ensuring children's voices are heard and building an understanding of family practices and culture (Backett-Milburn \& Harden, 2004; Gillies, Ribbens McCarthy, \& Holland, 2001; Lewis, Noden, \& Sarre, 2008; Millar \& Ridge, 2009). It is far less common, however, for children to be interviewed in the presence of parents (Curtis, 2007; Irwin \& Johnson, 2005) or to interview families as a group (Astedt-Kurki, Hopia, \& Vuori, 1999; Astedt-Kurki, Paavilainen, \& Lehti, 2001; Eggenberger \& Nelms, 2007; Holland, Mauthner, \& Sharp, 1996). Primarily, this is a response to concerns that, given generational power relations, the presence of parents may serve to influence, police, or silence children's voices (Harden, Backett-Milburn, Hill, \& MacLean, 2010; Holland et al., 1996). However, by making such methodological assumptions and, in turn, not generating group accounts with parents and children, we may be missing opportunities to add further methods to our toolkit and additional analytical dimensions to our explorations and understandings of the lives of families and children. More detailed reflection is required in this area to aid and inform researchers' understandings of the impact that parents' presence has on children's voices in qualitative research.

\section{Eliciting and representing children's voices}

The interdisciplinary field of childhood studies was, and continues to be, premised on the understanding of children as potentially articulate social actors, thereby challenging the longstanding research practice of accessing children's experiences by proxy via relevant adults, particularly parents. The emphasis on giving children a "voice" led many to explore children's lives outwith the family and, within family research, to include children directly but independently, in research. It is acknowledged that the cultural and social norms that shape social interactions within different contexts influence the possibilities that are available for the production of children's voices within such settings (Fox, 2013; Spyrou, 2011). Alanen (2001) argues that generation can be compared to other social structures, such as gender and class, claiming "the notion of a generational structure or order refers to a complex set of social processes through which people become (are constructed as) 'children' while other people become (are constructed as) 'adults'” (pp. 20-21). Concerns about the generational hierarchies that are at the heart of parent-child relationships are often at the forefront of the design of research with children and families. Specifically, there is a concern that interviewing children with parents present may result in a silencing or a dilution of children's voices. Punch (2005) highlights how, within everyday family life, differential power relations exist between children and parents as compared to children and siblings, contributing to children exerting more selfcontrol and demonstrating greater respect within the context of parental relationships while sibling relationships, albeit still characterized by power dynamics (Punch, 2007), enable a more open expression of thoughts and feelings. Thus, an attempt to guard against the potential overpowering and policing of children's voices by parents or other adult family members underlies the lack of research conducted with children and parents together (Holland et al., 1996).

However, in recent years, it has been suggested that, despite the fact that research with children is now far more commonplace, there is often a lack of critical reflection on the ways that 
researchers conceptualise, elicit, interpret, and represent children's voices (Komulainen, 2007; Spyrou, 2011) and the implications of this for claims that can be made about the authenticity of the voices reported (James, 2007). Due to the dearth of research conducted with children and parents together, there has been limited reflection from childhood and family researchers on their experiences with this method of research. Those who have utilised a group interview in the context of research with parents and children have suggested that in some contexts, not interviewing children and parents together may inhibit children's willingness to communicate with the researcher, and so may be acting to silence children's voices. In the context of the home, children (particularly younger children) may be accustomed to the presence of their parents and may take comfort and feel supported in a joint interview situation, thus allowing them to express their views in ways that might not be possible in an individual interview (Eggenberger \& Nelms, 2007; Irwin \& Johnson, 2005).

In this article, we reflect on our experiences of conducting family group interviews as the second wave of a qualitative longitudinal study, involving parents and children who gave individual accounts at the first and third/final waves. We explore the impact of parents' presence on children's voices, demonstrating how parents facilitated, modified, and policed children's accounts, while also showing evidence of children questioning and contradicting parents' accounts. We also discuss the analytical challenges presented by the data from these interviews. In reflecting on our experiences of conducting family group interviews, we focus on what can be learnt from the intergenerational interactions within the groups rather than the intra-generational or sibling dynamics. Firstly, this is because we principally wish to add to methodological discussions of the advantages and disadvantages of interviewing parents and children together. Secondly, we are limited in the extent that we can comment on intra-generational interactions by the fact that only four of the 12 family group interviews we conducted involved two or more siblings. By providing our reflections on the use of family group interviews, we hope to contribute to debates on the merits and challenges of this method of researching with children.

\section{Study Background}

"Work and family lives: the changing experiences of 'young' families” was a qualitative longitudinal study conducted in Scotland as part of the Timescapes initiative funded by the Economic and Social Research Council (ESRC). The study investigated: processes of negotiation between parents and their primary-school-aged children in addressing issues raised by working parenthood; how such issues impact on everyday family practices; and how these change over time in response to changes in work and family circumstances, including those in children's lives. The sample comprised 14 families recruited from a variety of employment, community, and education sites, five of which were lone-mother households and nine heterosexual-couple families. Fourteen mothers, eight fathers, and 16 children (aged between 7 and 11 years at the inception of the research) participated. All parents were in paid employment (11 full-time, nine part-time), apart from two who were retired for health reasons.

Three waves of data collection were conducted over a period of two years. Individual interviews were conducted with parents and children in Waves 1 and 3, with a family group interview in Wave 2. Fieldwork waves were on average nine months apart, from 2007 to 2009. Individual interviews were semi-structured and lasted one to two hours for parents and 30 
International Journal of Child, Youth, and Family Studies (2014): 5(4.1) 649-665

minutes to an hour for children. Children's interviews included some activities (e.g., drawing, vignettes, choosing from stickers of faces showing a range of emotions) as a springboard for discussion (Harden, Scott, Backett-Milburn, \& Jackson, 2000); parents also responded to some of the vignettes. Family interviews were also semi-structured and lasted one to two hours. We conducted family interviews with 12 of the 14 families in the sample because two families were recruited late to the study and only completed two waves of individual interviews. Family interviews included parents and children who had been interviewed at Wave 1, plus any younger siblings who also wanted to take part. They featured activities designed to encourage interaction and discussion between family members, which are discussed in more detail below. Each fieldwork wave had a thematic focus (experiences of time during a working day; experiences of weekends and holidays; values in relation to employment); however, changes over time in relation to work and family were also explored longitudinally. All interviews were conducted by the researcher, Alice MacLean (AM), in participants’ homes, apart from two individual interviews which were conducted at a university. Names used in this paper are pseudonyms.

\section{Research Design}

The central aims of our research - to explore how families experienced and negotiated the challenges presented by working parenthood - informed the design of the research in a number of ways. First, we selected a longitudinal design with the intention of exploring how families' lives changed over time and the impact this had on their experiences of working parenthood (Harden, Backett-Milburn, MacLean, Cunningham-Burley, \& Jamieson, 2013). Second, we chose to undertake both individual and a family group interview. We anticipated that individual interviews with parents and children would enable us to address our central aim, in part, by providing their separate accounts, which we then analysed together to reflect on the similarities, differences, shared stories, and gaps (Harden et al., 2010). However, we were also interested in family practices, that is, the notion of the family as actively created by its members; as something that people do rather than what people are (Morgan, 1996). While it is possible to explore family practices through individual interviews, we were keen to explore whether a family group interview would add to this understanding.

Researchers using this method have suggested that family group interviews can help “capture interactional data or shared meanings” (Astedt-Kurki et al., 2001, p. 291). It is this interactional nature of family group interviews that some have suggested can reveal the "tone and personality of a family [...] in a way that interviewing individual family members cannot" (Eggenberger \& Nelms, 2007, p. 209). It has also been noted that family group interviews are “a successful method for observing and recording patterns of control and negotiation during the conversation” (Holland et al., 1996, p. 14). We were also interested in exploring the interactions between children and parents in these contexts, and whether a public family story or "family front" (Holland et al., 1996, p. 14) would be upheld or challenged across the different interview contexts. While we have at no point viewed the family interviews data as wholly "naturally occurring” (Smithson, 2000, p. 105) or as representing the "real” family, we included family group interviews in our design because of their potential to offer something different to the individual interviews by bringing the group dynamics to the fore and allowing the interplay of relationships to become part of our understanding of the families' experiences. 
International Journal of Child, Youth, and Family Studies (2014): 5(4.1) 649-665

Despite the decision to undertake family group interviews we were very mindful, and indeed shared many of the concerns noted earlier. Careful consideration was given to the timing of the family group interview, the interview methods and the focus of the interview, and the ethical issues that may arise. We will discuss each in turn.

\section{Timing}

The longitudinal design of the study offered an opportunity to explore the potential of this method alongside individual interviews, so minimizing the risk that its use in a single interview study would have presented. We chose to conduct the family group interview as the middle wave of interviews, between the two rounds of individual interviews, because we anticipated that at that point, research relationships built during the first wave would facilitate the group interview. In particular, given the concerns about the potential impact on children's voices, we hoped that, at that stage, children would feel more at ease with the researcher and the context of the research interview having already undertaken the initial individual interview. However, we are not suggesting that there is a single best point at which to conduct family group interviews within the context of longitudinal or repeat interview research.

\section{Interview design}

To engage children and parents, stimulate interaction, and track change over time, we designed a chart that acted as the main activity in the groups. A sheet of A0 size paper was prepared in advance with columns along the horizontal axis representing the school terms and holidays which had passed since they had last been interviewed (e.g., October break, school term before Christmas holiday, et cetera.) and, from the left vertical axis, there was a row for each family member and a bottom row entitled "family". This personalised grid provided a framework for families to record what had been happening for them, both individually and as families, since their first interviews. After reminding families of when they had last been interviewed and providing basic details of what had been happening for each of them at that time (taking great care not to reveal any information to which all family members were not privy), participants were given pencils, pens, and different coloured and sized post-its and were invited to add to the chart using these. What was added to the chart was left up to participants and AM was deliberately vague and open in describing the completion of the chart. Typically, participants were asked to add "what's been happening" since they were last interviewed and if they asked for clarification they were given examples, such as things they had done, changes that had taken place, as well as things that had stayed the same over that period of time. We placed keywords around the chart to remind participants of the areas of their lives that we were interested in (e.g., school, work, family, friends, time, money, health, et cetera) and to encourage a wide range of additions to the chart. To capture not only what they had done but also how they felt about events or changes, parents and children were then invited to add emotion stickers to the chart.

Following the chart activity, families were asked to reflect on their experiences of weekends and holidays, a topic area that had been touched on in the individual interviews but which we felt was something that needed to be explored further. Initially this was done using a basic format where AM asked questions of the group without props or activities. However, after conducting two of the family group interviews, we found that children tended to lose interest in the discussion after the chart activity. To keep children engaged for the remainder of the 
International Journal of Child, Youth, and Family Studies (2014): 5(4.1) 649-665

interview, when interviewing subsequently we used a role-play technique whereby laminated cards were placed in the centre of the group. Each card had an interview question printed on it and all members of the group took turns to pick a card and to pretend to be the interviewer by asking the rest of the group the question. This worked well in engaging the children, as they were generally keen to take their turn to ask a question.

\section{Ethical concerns}

We also acknowledge that the wider discussion around the implications of using family group interviews, in terms of eliciting children's voices, is also an underlying ethical issue, which we hope the article, in its entirety, addresses. Here we focus on specific ethical issues raised by the use of family group interviews. As noted above, we considered very carefully the potential topic focus for the interview and deliberately avoided topics that we thought could be considered to be sensitive, for example financial concerns. While the potential impact of topics or question areas should always be considered when designing an interview, the family group interview presented the additional challenge of ensuring that the topics were not an area that parents and children would feel uncomfortable discussing together.

Clearly there is no absolute correct answer to this, as one family may feel happy to discuss what for another is taboo. We based our judgements on which topics to include on the data emerging from the individual interviews. For example, in the case of financial concerns, we noted an awareness of monetary issues and some indication of this as a difficult area for some of the children, which did not always appear to be communicated to parents. As a result, we did not feel that this was something suitable for group discussion. Nevertheless, in some families this issue arose spontaneously.

Moreover, it was also not always possible to anticipate what would be sensitive topics for families. The passing of time and occurrence of events between the first interview and the group interview also had an impact on families' reactions to some topics, which in turn called for careful facilitation. Depending on what had happened in their lives since their first interviews, raising and probing around even seemingly innocuous topics could prove difficult. In one group, a request to hear more about their summer holiday caused upset and the children seemed to panic at the prospect of talking about this. Their mother quickly curtailed the discussion, saying that they would rather not talk about the holiday because it had involved her ex-partner from whom she had only recently separated. This shows the way that seemingly mundane topics could become sensitive depending on what had happened since the previous interview.

We were also aware of the increased difficulty of ensuring network confidentiality when using this method as part of a longitudinal design. This refers to keeping the individual interview contents private from the respondent's family (Hill, 2005) and is pertinent to research with children and parents, given that members of a family may wish to know what the others have said when interviewed separately (Harden et al., 2010). AM ensured that she was very familiar with the individual interviews carried out in Wave 1, noting shared topics of discussion and those raised only by the individual members. When discussing change during the time period between Wave 1 and Wave 2, she was also careful to summarise the family's situation in very general terms. 
International Journal of Child, Youth, and Family Studies (2014): 5(4.1) 649-665

Family group interviews also present the potential for tensions in relationships between parents or between parents and children to become evident. This poses additional challenges to the researcher and may require considerable sensitivity in handling potentially difficult situations. We discuss this sense of experiencing "relationships in action" below.

\section{Reflections on Conducting Family Group Interviews}

\section{Eliciting children's voices}

Despite our concerns about children being silenced, in practice there were very few examples of parents talking over, or instead of, children. In the majority of the groups, children seemed to contribute enthusiastically and often. Nevertheless, there were ways in which we noted that parents seemed to influence their children's accounts, for example by modifying their more negative comments to present things in a more positive light. In one group, when talking about their holiday, while the son (Robert) dwelt on their mistakes or things that had gone wrong, his dad (Hugh) tried to downplay the negatives and emphasised the good time they had:

Hugh: Yeah, yeah, we went to [Canada].

[...]

Robert: Oh, aye. That wasn't very nice.

Hugh: It was lovely.

Robert: You forgot the bed!

Hugh: Oh well minor...

I: What happened?

Robert: They forgot my bed!

[...]

Hugh: But when we got there it was late at night [...] there was only a double bed, no bed for him, you know [...] Aye, it wasn't the best place in the world I've ever stayed in [...]

But we had a good time, it was a great time.

Equally there were instances where it appeared that parents also facilitated their children's contribution. On occasions, AM asked questions to the group and parents directed them to the children, implying they would be able to answer best. Parents also reminded children of things that they had done, so facilitating their voices by bringing them into the discussion more. There was also evidence of children questioning and contradicting the accounts of parents and siblings. For instance, in one group, the middle of three sisters commented negatively on all the activities her sisters and parents noted on the chart. For example when her father said they had been for a nice meal she made a retching sound and said it was the worst meal ever.

Somewhat unexpectedly, instead of children being the quieter presence, it was at times one or other of the parents who contributed little to the group dialogue. In one group, it was the father who said very little and at times both his wife and children spoke for him. This was interesting given that his individual account had been detailed and articulate. It suggests that either the group dynamics prevented him from having a strong voice or that he chose to have a quieter presence in the group situation. There was also evidence of parents modifying and policing one another's accounts. In one group, there was an interesting dynamic between the parents whereby the mother seemed to look to her husband for permission or back-up to her 
International Journal of Child, Youth, and Family Studies (2014): 5(4.1) 649-665

statements, asking him "is that okay?” and "is that not important?". AM got a sense that she was looking for more input from him whereas he seemed guarded and perhaps not entirely comfortable with what she was revealing.

The family group interviews gave us some insight into the tensions, constructions, and negotiations of relationships within families. Again, we see evidence of children's agency in negotiating these relationships, rather than the silencing of them in the context of the group interview.

\section{Relationships in action}

Participants' interactions in the family interviews also sometimes suggested the existence of tensions in relation to events and relationships within their family. The extracts below, with Gail (lone mother) and her 12-year-old daughter Heather, exemplify this:

Gail: I suppose the other thing that's a real change for you [Heather] is you've been spending a lot of time with your dad that you've never really done. She's been practically living at her dad's house [since the renovations on our house started]. Heather: I do live at dad's house.

Gail: Because we thought by the time you got back [from school camp] it [the renovations] would be all alright. How foolish we were. Heather: How foolish you were...

Later when talking about weekends and future changes:

Heather: Well, I go swimming a lot and I go round and see my friends and things like that and they... well, they don't come round here because it's disgusting. Well, it is. It's horrible. [...]

Gail: Yeah, if we can get the house finished that'll be...

Heather: My room. I don't care about the house, I want my room back.

Gail: Yeah, well that'll happen...

Heather: You can't be bothered.

However, the interactions also exemplified relationships in other ways. The family interviews gave us an insight into the ways "childhood” was enacted within families. In the individual interviews with parents, there was a sense in the parents' accounts that children should be shielded from financial worries and responsibilities and we saw evidence of this in the family interviews. The Watsons (father Graham, mother Sheila, and 10-year-old son Lewis) talked openly about how they had far less money than they used to as a result of Graham starting up a new business and increasing everyday expenses as a result of the recession:

Graham: We eat a lot of root vegetables! And the price of food is going through the roof! Lewis: Is it?

Sheila: Yes, I mean, you do notice things like that, that just ordinary...

Graham: Bread, rolls, rice is really expensive.

Lewis: I don't notice that.

Sheila: Well no and why should you? 
International Journal of Child, Youth, and Family Studies (2014): 5(4.1) 649-665

The fact that Graham and Sheila spoke frankly throughout the group about how much their financial circumstances had changed suggests Lewis already knew this or that they were not trying to hide these facts from him. However, Lewis's contributions to this exchange give the impression that he knew little about the rising costs to which his parents were also adjusting. Sheila's response, “Well no and why should you?”, could be read as implying that she thought that Lewis, as a child, should not be expected to know or worry about such things.

There was also evidence of children negotiating future changes relating to their independence. Lisa (age 12), while being interviewed with her mother Jane, brought up changes she would like to happen when talking about an ideal weekend:

Lisa: Like sort of maybe like go out shopping with my friends, like early in the morning [...] Like somewhere different that I've never been on my own before... Jane: I was wondering when this one was coming.

Lisa: Somewhere like [shopping centre in city centre]. But I would go with like one of my friend's parent dropped me off there and then say like we all meet back at like say [shopping centre] at like... pick you up there. Just like free time sort of thing. Jane: [Sighs]

Jane's comment, "I was wondering when this one was coming”, suggests she had sensed that Lisa wanted to negotiate this change and was anticipating her raising it at some point. It is possible that Lisa did so in the family interview because she thought her mother would be under increased pressure to grant the request. Again, this shows how the family interviews provided a lens through which to view the processes involved as parents and children negotiate change over time. It is impossible to know whether these "questions" would have been asked in the course of day-to-day family life and if they would have been asked in the same ways, or if the family interviews gave children and parents a space in which to raise these issues. Nevertheless, these interactions provided us with a different perspective, which we would not have accessed had we only conducted individual interviews (Bushin, 2009; Eggenberger \& Nelms, 2007; Irwin \& Johnson, 2005; Punch, 2007).

The relationships between parents and children were often clearly evident in the group interviews and while this provided very interesting data and an insight into the ways in which family practices are negotiated, it was also challenging at times for the researcher. This raises wider questions about the role of the researcher within the context of these interviews.

\section{The role of the researcher}

AM conducted each family group interview alone. Her reflective notes highlight some of the concerns she felt about engaging with multiple family members in a very different context than her initial meetings with them:

When I started conducting the family interviews, one of my first feelings was that it was like walking a tightrope between all the relationships that I'd started to develop with the individual participants in the first wave. It felt like it was impossible to please everyone and I came away from some groups concerned that the children were disappointed with 
International Journal of Child, Youth, and Family Studies (2014): 5(4.1) 649-665

how I'd interacted with them in the groups, so I questioned whether I was able to build on existing relationships through the group context.

Indeed the researcher is positioned very differently in the context of the family group interview. Managing the group dynamics single-handedly was a significant challenge of facilitating the family group interviews, as family life did not stop when the interview began. The interview was often interrupted by phone calls, different family members not involved in the interview coming and going, arrangements being made, and so on. Yet it is perhaps these multiple events that represent the "doing family" that we were seeking to capture. When together, many families will not be ordered, speaking in turn, remaining focused on a single topic or task. This messiness of family life may be part of what we hope to access via the family group interview but it also proved challenging for the researcher. As in other interview contexts, researchers need to make on the spot decisions about whether to let the interview conversation go in any direction the interviewee takes it, or whether there are times when the researcher needs to refocus the discussion. In family contexts there is an additional challenge given that the distractions, interruptions, conversational tangents, and so on that "disrupt" the interview may inform what we are researching: that is, they may give us an insight into the family relationships and processes of negotiation between family members.

Moreover, as researchers in this context, we are stepping into established relationships, and in the case of parents, children, and their siblings, hierarchical relationships based on their different generational positions (Alanen, 2001; Mayall, 2001; Punch, 2005). There were occasions when parents dominated the interviews in various ways. In one group, the mother dominated whenever she could by talking about her work or financial concerns. In another, the mother took control over filling in the chart for everybody and the children complained, saying "mum, why are you filling in all the chart?" (Anna). As other researchers have found in similar situations (Bushin, 2009; Punch, 2007), AM found it difficult to take control in order to redress the power imbalance without this perhaps being interpreted as undermining the parents. On another occasion, a father commented on how AM was facilitating the group, telling her that she should give the children more direction. There were also times when parents' abilities to take control were perceived by AM as helpful, such as quietening dominant children in order to give others a say or preventing outspoken children from dictating the pace or direction of discussion. These instances highlight the complex nature of the power relations, which the researcher becomes part of, and through which the researcher has to navigate. Although these instances could be difficult to manage, we also came to value them as a way of seeing family dynamics and hierarchies being acted out through the activities conducted in the family group interviews. For the most part these interactions show how parents, children, and indeed AM, assumed and accepted parents as being highest on the power hierarchy, and thus in greater control (Punch, 2005). However, we have also shown how children tried to challenge parents' positions and attempted to negotiate more control in this context.

When deciding to use family group interviews, we recognised that non-verbal communication and aspects of group dynamics that could not be picked up through transcription of an audio recording were an important aspect of the data. We discussed whether to involve a second researcher to act as an observer in the group interviews but decided that this may be 
International Journal of Child, Youth, and Family Studies (2014): 5(4.1) 649-665

overwhelming for families and so may limit their engagement. While we have not necessarily changed our view on that, it proved to be extremely challenging for AM to simultaneously note and record such non-verbal interactions while facilitating the interview. In practice, AM attempted to capture as many aspects as she could of the non-verbal communication, dynamics, and roles within the group by writing detailed field notes after each interview. For example here are her field notes following the Wilson family interview:

There was an awkward exchange between Andrew [father] and Marie [mother] when they talked about the changes they were planning to make to their house. While she talked about their plans, Andrew tapped Marie on the arm, where Tom [their son] couldn't see. He seemed to be worried that she would say too much or maybe was concerned that she would reveal something that Tom didn't yet know about. I had to think quickly about what to ask next in order to avoid an uneasy silence.

However, we recognise that without a systematic means of observing non-verbal exchanges, it may only have been the more exceptional situations that were captured and many of the more subtle aspects may have been missed.

\section{Reflections on Analysing Family Group Interview Data}

Analysing the perspectives of multiple family members is a complex task (Ribbens McCarthy, Holland, \& Gillies, 2003). Indeed, one of our concerns about incorporating family group interviews into this study was the challenge of analysing the individual accounts of multiple family members alongside accounts with those same family members in a group context (Harden et al., 2010). In the discussion below we reflect on some of these challenges.

\section{Integrating family group and individual interview data}

The analysis of the family group interview data was informed and enhanced by linking those data with the individual interview data. In the example we gave earlier of the tensions between Gail and her daughter Heather, had we only the family interview data to draw on, the dynamics of this exchange may have been hard to unpick. Nevertheless, being able to refer back to Gail's first interview, in which she expressed concerns about her relationship with Heather and that she felt envious towards the children that Gail spends time with in her job as a support worker, enabled a deeper understanding of Heather's behaviour throughout the family interview. It is possible that having already felt that aspects of her relationship with her mother were lacking, such as doing things and going places together, Heather felt increasingly shut out, and in turn resentful, when the renovations meant she had to move in with her father.

However, the analytic integration of group and individual interview accounts is not always straightforward. One of the key analytic challenges we faced was making sense of contradictions and changes across individual and group accounts, and between family members. As a qualitative longitudinal study we were interested in tracking change over time and this presented additional challenges to the analysis of the group interviews. This is a quote from Jan Ritchie, a mother of three who was on maternity leave when first interviewed. Talking about the prospect of going back to work, she said, "at the moment I could just weep at the thought of going back". Jan's dread of her imminent return to work was a major theme in this interview, so 
International Journal of Child, Youth, and Family Studies (2014): 5(4.1) 649-665

we were keen to follow it up during their family interview. In the family interview, nine months later they said:

Jan: When did I go back [to work]?

Calum: Back to work [reads off calendar and laughs]. Sad face.

Jan: [Laughs] Well, no actually, it's been fine.

Calum: [Laughs] Has it?

Later in the group, Jan's daughter, Anna, also gave her view that Jan had felt very sad about going back to work. In the family group setting, it would have been unethical to probe by referring back to the level of Jan's anxiety in her first interview, so in terms of tracking and exploring change over time we are left with a sense that information has been lost and our understanding of this change is incomplete at this stage. It was not until Jan's next interview, 18 months after her first, that AM was able to explore in more detail her return to work. Instead of the entirely positive gloss given by her to this change during the family interview, she acknowledged in her last interview that "everything's going as well as it could" and that although one of her children was still not happy about the situation, they would simply have to accept it. This example highlights, as noted earlier, that intergenerational power relations are evident both in the content of what is discussed, and the manner in which the issue is discussed in the group. While both the children gave the impression that the return to work had been experienced as a negative change, Jan was quick to correct them and present it more positively. This example also indicates that we may be accessing different accounts in the family and individual interviews. Although Jan spoke openly about the challenges of the return to work, in both of her individual interviews, her very positive account in the family interview may have indicated that she did not want to acknowledge any difficulties directly, in the presence of the children, despite the fact that the children's accounts indicate they were well aware of problems.

The way that we addressed these different accounts was shaped by our epistemological stance. We were not seeking to find a single "truth" or to triangulate the accounts as some form of corroboration of a family reality. Instead, drawing on interpretivist traditions, we adopted what has been referred to as a bird's eye view (Ribbens McCarthy et al., 2003) highlighting the analyst's ability to have an overview of all family members' accounts and, for example, to see and interpret in a detailed context where these agree and contradict in order to provide an interpretation, one that did not claim to be the "truth" but that was grounded in the data (Perlesz \& Lindsay, 2003).

\section{Non-verbal data}

While AM did not systematically record non-verbal interactions, her field notes were very useful in offering additional data through which to make sense of the families' accounts. For example, here she reflected on an incident during the Erskine family interview.

When adding post-its to the chart, Jack asked if it was only good things they were supposed to put on. When I said he could put any changes on, he added that his mum's boyfriend had left and Evie also put this on the chart. When using the smileys, Jack and Evie both went for sad faces first and put them on this change. This was an awkward moment. Rachel made eye contact with me, she looked 
International Journal of Child, Youth, and Family Studies (2014): 5(4.1) 649-665

concerned and seemed to be saying "this is difficult, please don't ask any questions” - which I didn't.

It was also useful to note observations regarding the roles adopted during the interview. In many of the interviews it was the mother who oversaw the chart activity or who the others looked to for information and direction (e.g., asking what they did and when they did it and younger children also asked what they should write), reflecting the evidence from the individual interviews that it was the mothers who were most involved in organizing the family's lives (Harden, MacLean, Backett-Milburn, \& Cunningham-Burley, 2012; McKie, Gregory, \& Bowlby, 2002). In addition to monitoring who took the lead, it was also interesting to note cases where a family member did not participate. For example in the Clarke family interview, the father, Alan, was silent through much of the interview. He may simply have been tired or less interested in taking part in the group interaction, but drawing on the individual interviews we can offer a different interpretation. His first interview portrayed a deep sense of antagonism towards his partner - he was very critical of how much she contributed to the family. There was nothing within the accounts of the children or the mother, Maggie, that indicated that this was a feeling they were all aware of, so he may have used the individual interview to express how he felt and was then "silenced" in the group context.

\section{Family group interviews: the private and the public}

We have seen, above, how private tensions are at times enacted in family group interviews. As part of our analysis we explored the ways in which what children and parents said in the family interviews may have been controlled, inhibited, or facilitated by one another's presence and utterances. However, it also became clear that there was a sense of awareness of the family group interview as "public". While this notion of private and public accounts in interviews has been noted in relation to individual interviews (Cornwell, 1984), it is the negotiation of this public face that is interesting in the context of family group interviews. This was most evident in relation to the construction of the chart. There were many examples of discussions and disagreements among families about what should be added to the chart, suggesting participants were thinking about how people who might view the chart would perceive what they had written on it. Jan objected to her husband's suggestion that they should add that their youngest son was ill with sickness and diarrhoea when he started going to nursery upon her return to work, saying "Do we really need to put that? We don't really". Given the significance of this event for them as a family, as noted above, it is interesting that she did not want this recorded. There were also instances of parents editing what children wanted to add to the chart. In one group, Paul (age 5), who was one of the youngest children to take part in the family interviews, was keen to fill his section of the chart and wanted to add the fact that he had recently got a filling in one of his teeth. In response to his suggestion, his mother sighed and said “okay, but it was a very minor filling honey". Again, this implies a concern, on the part of Paul's mother, that those who might see the chart may judge her as a parent due to her son having a filling.

The children also commented on each other's contributions. In one group, Ashley (age 9) suggested that his brother Ryan (also age 9) should write on the chart that he got the "all clear" after being hospitalized. However, Ryan responded by saying "that's my privacy, I'm not writing it on paper". Interactions such as this suggest a tension between the notion of the chart as a 
International Journal of Child, Youth, and Family Studies (2014): 5(4.1) 649-665

public document and the private nature of the issues the activity often raised. Thus, we interpreted the family interviews data as co-constructed performances shaped by context and participant awareness of "the public that is being addressed" (Morris, 2001, p. 556), whether this was the others in their family, the researcher, or the wider public audience who may come into contact with the data. These interactions suggest that the chart activity may be an effective means of exploring the normative standards that impact upon the ways in which families and family life is displayed (Dermott \& Seymour, 2011; Finch, 2007; Haldar \& Waerdahl, 2009) in the somewhat public context of research. They also suggest that, at least for the families in our study, the research team and other research "users" could be considered as among the "multiple potential audiences" who matter when it comes to the display of family (Dermott \& Seymour, 2011, p. 14).

\section{Conclusion}

One of the central aims, and indeed an ethical responsibility of qualitative research, is to ensure that the context within which the research is conducted enables the participants to tell their stories, that is, that we ensure their voices are heard. Research with children has rightly questioned the authenticity of hearing children's voices by proxy, interpreted by key adults. However this may have led to an assumption that including children as independent participants in research provides us with an authentic voice and neglects the potential of methods that include the involvement of parents. We have suggested that, in our study, family interviews assisted us in making sense of the multiple perspectives of family members often presented in fragmented form via indivdual interviews alone. In addition, the family interviews may have facilitated children's voices by providing them with a supportive, comfortable context within which to take part in research; and the opportunity to voice grievances, ask questions, and to negotiate relationships and change. We do not claim that by using the method we can elicit more authentic voices or that we can see the "real" family in action. Indeed we have addressed the ways in which we understood the interview to be, in part, a public performance. Moreover it is a method that presents particular ethical and practical challenges. Nevertheless, our experience with family group interviews has led us to conclude that it is a useful and interesting method to add to the toolkit for use in research with children in the context of families. 
International Journal of Child, Youth, and Family Studies (2014): 5(4.1) 649-665

\section{References}

Alanen, L. (2001). Explorations in generational analysis. In L. Alanen \& B. Mayall (Eds.), Conceptualizing child-adult relations (pp. 11-22). London: Routledge Falmer.

Astedt-Kurki, P., Hopia, H., \& Vuori, A. (1999). Family health in everyday life: A qualitative study on well-being in families with children. Journal of Advanced Nursing, 29(3), 704711. http://dx.doi.org/10.1046/j.1365-2648.1999.00941.x

Astedt-Kurki, P., Paavilainen, E., \& Lehti, K. (2001). Methodological issues in interviewing families in family nursing research. Journal of Advanced Nursing, 35(2), 288-293. http://dx.doi.org/10.1046/j.1365-2648.2001.01845.x

Backett-Milburn, K., \& Harden, J. (2004). How children and their families construct and negotiate risk, safety and danger. Childhood, 11(4), 429-447. http://dx.doi.org/10.1177/0907568204047105

Bushin, N. (2009). Interviewing with children in their homes: Putting ethical principles into practice and developing flexible techniques. In L. van Blerk \& M. Kesby (Eds.), Doing children's geographies. Methodological issues in research with young people (pp. 9-25). Abingdon, UK: Routledge.

Cornwell, J. (1984). Hard-earned lives: Accounts of health and illness from East London. London: Tavistock.

Curtis, P. (2007, March). Space to care: Research with children in hospital settings. Paper presented at the Children's Participation in Research Processes: Putting Theory into Practice, University of Sheffield.

Dermott, E., \& Seymour, J. (2011). Developing 'displaying families’: A possibility for the future of the sociology of personal life. In E. Dermott \& J. Seymour (Eds.), Displaying families: A new concept for the sociology of family life (pp. 3-18). Basingstoke, UK: Palgrave Macmillan.

Dermott, E., \& Seymour, J. (Eds.). (2011). Displaying families. A new concept for the sociology of family life. Basingstoke, UK: Palgrave Macmillan.

Eggenberger, S. K., \& Nelms, T. P. (2007). Family interviews as a method for family research. Journal of Advanced Nursing, 58(3), 282-292. http://dx.doi.org/10.1111/j.1365-2648.2007.04238.x

Finch, J. (2007). Displaying families. Sociology, 41(1), 65-81.http://dx.doi.org/10.1177/0038038507072284

Fox, R. (2013). Resisting participation: Critiquing participatory research methodologies with young people. Journal of Youth Studies, 16(8), 986-999. http://dx.doi.org/10.1080/13676261.2013.815698 
International Journal of Child, Youth, and Family Studies (2014): 5(4.1) 649-665

Gillies, V., Ribbens McCarthy, J., \& Holland, J. (2001). Pulling together, pulling apart: The family lives of young people. London: Family Policy Studies Centre for the Joseph Rowntree Foundation.

Haldar, M., \& Waerdahl, R. (2009). Teddy diaries: A method for studying the display of family life. Sociology-the Journal of the British Sociological Association, 43(6), 1141-1150. http://dx.doi.org/10.1177/0038038509345694

Harden, J., Backett-Milburn, K., Hill, M., \& MacLean, A. (2010). Oh, what a tangled web we weave: Experiences of doing 'multiple perspectives' research in families. International Journal of Social Research Methodology, 13(5), 441-452. http://dx.doi.org/10.1080/13645571003650979

Harden, J., Backett-Milburn, K., MacLean, A., Cunningham-Burley, S., \& Jamieson, L. (2013). Home and away: Constructing family and childhood in the context of working parenthood. Childrens Geographies, 11(3), 298-310. http://dx.doi.org/10.1080/14733285.2013.812274

Harden, J., MacLean, A., Backett-Milburn, K., \& Cunningham-Burley, S. (2012). The 'familywork project': Children's and parents' experiences of working parenthood. Families, Relationships and Societies, 1, 207-222. http://dx.doi.org/10.1332/204674312x645529

Harden, J., Scott, S., Backett-Milburn, K., \& Jackson, S. (2000). Can't talk, won't talk?: Methodological issues in researching children. Sociological Research Online, 5(2), http://socresonline.org.uk/5/2/harden.html.

Hill, M. (2005). Ethical considerations in researching children's experiences. In S. M. Greene \& D. M. Hogan (Eds.), Researching children's experiences (pp. 61-86). London: Sage. http://dx.doi.org/10.4135/9781849209823.n4

Holland, J., Mauthner, M., \& Sharp, S. (1996). Family matters: Communicating health messages in the family. London: Institute of Education.

Irwin, L. G., \& Johnson, J. (2005). Interviewing young children: Explicating our practices and dilemmas. Qualitative Health Research, 15(6), 821-831. http://dx.doi.org/10.1177/1049732304273862

James, A. (2007). Giving voice to children's voices: Practices and problems, pitfalls and potentials. American Anthropologist, 109(2), 261-272. http://dx.doi.org/10.1525/aa.2007.109.2.261

Komulainen, S. (2007). The ambiguity of the child's 'voice' in social research. Childhood-a Global Journal of Child Research, 14(1), 11-28. http://dx.doi.org/10.1177/0907568207068561

Lewis, J., Noden, P., \& Sarre, S. (2008). Parents' working hours: Adolescent children's views and experiences. Children and Society, 22(6), 429-439. http:/dx.doi.org/10.1111/j.1099-0860.2007.00124.x

Mayall, B. (2001). Understanding childhoods: A London study. In L. Alanen \& B. Mayall (Eds.), Conceptualizing child-adult relations (pp. 114-129). London: Routledge Falmer. 
International Journal of Child, Youth, and Family Studies (2014): 5(4.1) 649-665

McKie, L., Gregory, S., \& Bowlby, S. (2002). Shadow times: The temporal and spatial frameworks and experiences of caring and working. Sociology, 36(4), 897-924. http://dx.doi.org/10.1177/003803850203600406

Millar, J., \& Ridge, T. (2009). Relationships of care: Working lone mothers, their children and employment sustainability. Journal of Social Policy, 38, 103-121. http://dx.doi.org/10.1017/s0047279408002572

Morgan, D. L. (1996). Family connections. Cambridge, UK: Polity.

Morris, S. M. (2001). Joint and individual interviewing in the context of cancer. Qualitative Health Research, 11(4), 553-567. http://dx.doi.org/10.1177/104973201129119208

Perlesz, A., \& Lindsay, J. (2003). Methodological triangulation in researching families: Making sense of dissonant data. International Journal of Social Research Methodology, 6(1), 2540. http://dx.doi.org/10.1080/13645570305056

Punch, S. (2005). The generationing of power: A comparison of child-parent and siblings relations in Scotland. Sociological Studies of Children and Youth, 10, 169-188. http://dx.doi.org/10.1016/s1537-4661(04)10009-3

Punch, S. (2007). "I felt they were ganging up on me": Interviewing siblings at home. Children's Geographies, 5(3), 219-234. http://dx.doi.org/10.1080/14733280701445770

Ribbens McCarthy, J., Holland, J., \& Gillies, V. (2003). Multiple perspectives on the 'family lives' of young people: Methodological and theoretical issues in case study research. International Journal of Social Research Methodology, 6(1), 1-23. http://dx.doi.org/10.1080/13645570305052

Smithson, J. (2000). Using and analysing focus groups: Limitations and possibilities. International Journal of Social Research Methodology, 3(2), 103-119. http://dx.doi.org/10.1080/136455700405172

Spyrou, S. (2011). The limits of children's voices: From authenticity to critical, reflexive representation. Childhood-a Global Journal of Child Research, 18(2), 151-165. http://dx.doi.org/10.1177/0907568210387834 